\title{
SISTEM PENDUKUNG KEPUTUSAN KENAIKAN PANGKAT DI SMA NEGERI 1 LEMBANG JAYA KABUPATEN SOLOK MENGGUNAKAN METODE PROFILE MATCHING
}

\author{
Eko Amri Jaya ${ }^{1}$, Indah Febriyani ${ }^{2)}$, Suci Rahmadhani ${ }^{3)}$ \\ ${ }^{123}$ Sistem Informasi, Sekolah Tinggi Teknologi Industri Padang \\ email : ekoamrijaya@sttind.ac.id ${ }^{1)}$,indahfebriyani@sttind.ac.id ${ }^{2)}$, suci.ratra27@gmail.com ${ }^{3)}$
}

\begin{abstract}
Abstrak : SMA Negeri 1 Lembang Jaya adalah salah satu sekolah di Kabupaten Solok dan pada saat ini proses kenaikan pangkat bagi guru honorer masih menerapkan sistem manual, yang memerlukan waktu lama dalam melakukan pengisian data kenaikan pangkat. Oleh karena itu, SMA Negeri 1 Lembang Jaya membutuhkan sistem yang baru untuk memudahkan dalam melakukan pengisian data agar lebih efektif dan efisien. Sistem pendukung keputusan dengan metode Profile Matching dirancang agar bisa membantu dalam pengambilan keputusan untuk memecahkan masalah yang bersifat semi terstruktur ataupun tidak terstruktur. Bahasa pemrograman Visual Basic 6.0 digunakan untuk membangun sistem pendukung keputusan, Microsoft Office Access sebagai pendukung untuk media penyimpanan data, dan Crystal Report. Dengan sistem pendukung keputusan ini dapat memudahkan pihak sekolah dalam melakukan proses kenaikan pangkat bagi guru honorer. Metode Profile Matching akan memberikan informasi yang lebih akurat untuk kenaikan pangkat dengan penilaian menurut kriteria yang telah ditetapkan.
\end{abstract}

Kata kunci : SPK, Profile Matching, Visual Basic 6.0, Microsoft OfficeAccess,Crystal Report

Abstract : SMA Negeri 1 Lembang Jaya is one of the schools in Solok Regency and at the moment the promotion process for honorary teachers is still implementing a manual system, which requires a long time to fill in the promotion data. Therefore, SMA Negeri 1 Lembang Jaya needs a new system to make it easier to fill data to make it more effective and efficient. Decision support systems using the Profile Matching method are designed to help in making decisions to problems solving that are semistructured or unstructured. Visual Basic 6.0 programming language is used to build a decision support system, Microsoft Office Access as a support for data storage media, and Crystal Report. With this decision support system, it is easier for schools to make promotions for honorary teachers. The Profile Matching method will provide more accurate information for promotions by rating according to established criteria.

Keywords: SPK, Profile Matching, Visual Basic 6.0, Microsoft Office Access, Crystal Report

\section{PENDAHULUAN}

Dalam suatu organisasi pendidikan memiliki jumlah pegawai yang cukup banyak sehingga dalam jangka waktu tertentu setiap pegawai mendapatkan kesempatan untuk kenaikan pangkat atau jabatan. SMA Negeri 1 Lembang Jaya Kabupaten Solok merupakan salah satu sekolah di Kabupaten Solok yang proses kenaikan pangkat bagi guru honorernya masih menggunakan sistem yang manual, sehingga dalam pengisian data kenaikan pangkat memerlukan waktu yang cukup lama. Dalam penilaian kenaikan pangkat terdapat beberapa kriteria - kriteria yang akan menjadi dasar penilaian yaitu tanggung jawab, disiplin, berdedikasi, bersosialisasi, mencintai peserta didik, menguasai ilmu pengetahuan dan mengelola kelas. Untuk mempermudah sekolah dalam mengambil keputusan kenaikan pangkat seorang pegawai, suatu organisasi pendidikan membutuhkan sebuah sistem pengambilan keputusan yang bisa membantu kepala sekolah untuk pengambilan keputusan yang akan di buat.

Kenaikan pangkat ini juga dapat dijadikan sebagai umpan balik terhadap 
prestasi mengajar di tempat mengabdikan diri sebagai guru pengajar. Sistem pendukung keputusan yang dirancang ini dapat membantu dalam pengambilan keputusan dengan memanfaatkan teknologi komputer. Hal lain yang perlu dipahami adalah bahwa sistem pendukung keputusan yang dibuat ini tidak untuk menggantikan tugas kepala sekolah tetapi hanya digunakan sebagai bahan pertimbangan bagi kepala sekolah dalam menentukan keputusan akhir.

Sistem pendukung keputusan adalah sistem berbasis komputer interaktif, yang dapat membantu para pengambil keputusan untuk menggunakan data dan berbagai model dalam memecahkan masalah - masalah yang tidak terstruktur. Menurut Binczek sistem pendukung keputusan merupakan sistem berbasis komputer yang terdiri atas tiga komponen yang berinteraksi satu sama lain yaitu sistem bahasa, sistem pengetahuan, dan sistem pemrosesan.

Proses pengambilan keputusan mempunyai tiga tahapan utama yaitu inteligensi, desain, pilihan. Kemudian ditambahkan dengan tahapan keempat yakni implementasi.

Profile matching adalah suatu proses penting dalam manajemen SDM dimana kita terlebih dahulu menentukan kompetensi (kemampuan) yang diperlukan dalam suatu jabatan. Secara garis besar proses dalam profile matching merupakan proses membandingkan antara kompetensi individu dengan kompetensi jabatan sehingga kita dapat mengetahui perbedaan kompetensinya.

\section{METODE PENELITIAN Lokasi Penelitian}

Penelitian yang bertempat di SMA Negeri 1 Lembang Jaya Kabupaten Solok ini dilakukan pada bulan Juni tahun 2019.

\section{Data Yang Dibutuhkan}

Data yang dibutuhkan dalam penelitian ini adalah sebagai berikut :
1. Data Primer yaitu data - data guru honorer yang akan menerima posisi untuk kenaikan jabatan.

2. Data Sekunder yaitu data - data yang dikumpulkan dari berbagai macam sumber seperti buku literatur, jurnal, makalah dan data umum (persyaratan untuk kenaikan jabatan) pada SMA Negeri 1 Lembang Jaya Kabupaten Solok.

Sumber data yang diperoleh berasal dari hasil pengamatan dan pengambilan data pada jurnal, buku literatur, dan data SMA Negeri 1 Lembang Jaya Kabupaten Solok.

Untuk mendapatkan informasi dan data - data yang dibutuhkan ada beberapa metode yang bisa digunakan yaitu sebagai berikut :

1. Metode Observasi, melakukan observasi atau pengamatan secara langsung untuk mendapatkan informasi beserta data yang dibutuhkan di SMA Negeri 1 Lembang Jaya Kabupaten Solok.

2. Metode Wawancara, melakukan wawancara langsung ke SMA Negeri 1 Lembang Jaya Kabupaten Solok.

3. Studi kepustakaan, sumber - sumber berupa buku, artikel, dan sumber sumber lainnya dikumpulkan sebagai acuan dalam sistem pendukung keputusan kenaikan jabatan.

\section{Evaluasi Sistem Yang Sedang Berjalan}

Sebelum perancangan terhadap sistem yang baru dilakukan, diperlukan gambaran terhadap sistem yang sedang berjalan pada SMA Negeri 1 Lembang Jaya Kabupaten Solok mengenai pendukung keputusan kenaikan pangkat. Hal ini bertujuan agar mempermudah kita dalam merancang sistem baru sehingga sesuai dengan yang kita diinginkan. Dengan kata lain sistem lama ini dijadikan sebagai bahan perbandingan dalam perancangan sistem yang baru, yaitu sebuah sistem pendukung keputusan kenaikan pangkat bagi guru honorer SMA Negeri 1 Lembang Jaya 
Kabupaten Solok dengan menggunakan metode Profile Matching.

Berdasarkan gambaran proses yang ada pada sistem pendukung keputusan kenaikan pangkat pada SMA Negeri 1 Lembang Jaya Kabupaten Solok dilakukan pengamatan dan penelitian yang bertujuan untuk memudahkan kepala sekolah untuk memproses data - data mengenai kenaikan pangkat bagi guru honorer di SMA Negeri 1 Lembang Jaya Kabupaten Solok.

\subsection{Aliran Sistem Informasi}

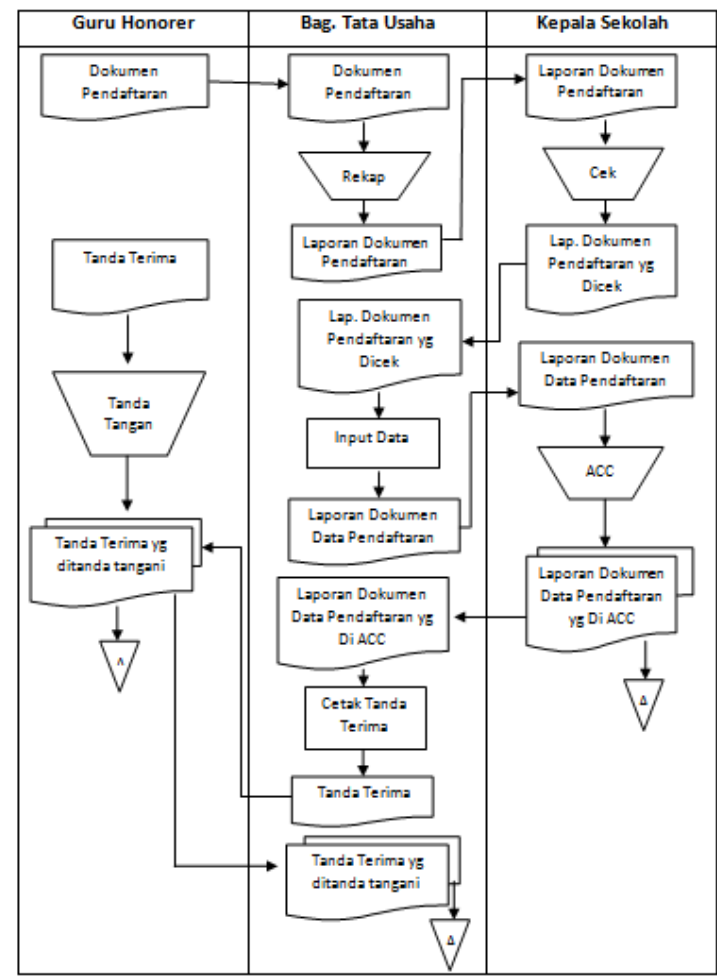

Gambar 1. Aliran Sistem Informasi

Melakukan perubahan terhadap beberapa proses pengolahan data dan proses pembuatan laporan pada aliran sistem informasi diatas. Hal ini bertujuan agar setiap kendala yang terjadi pada sistem pengolahan data yang lama dapat diatasi, seperti pembuatan laporan data guru serta data kenaikan pangkat yang akan diproses dengan bantuan dari program aplikasi. Keuntungan perubahan terhadap sistem ini yaitu lebih cepat dalam proses pengolahan data, keamanan data menjadi lebih terjamin dan tingkat kejenuhan dari pemakai sistem juga dapat teratasi dengan penerapan perubahan ini.

\subsection{Context Diagram}

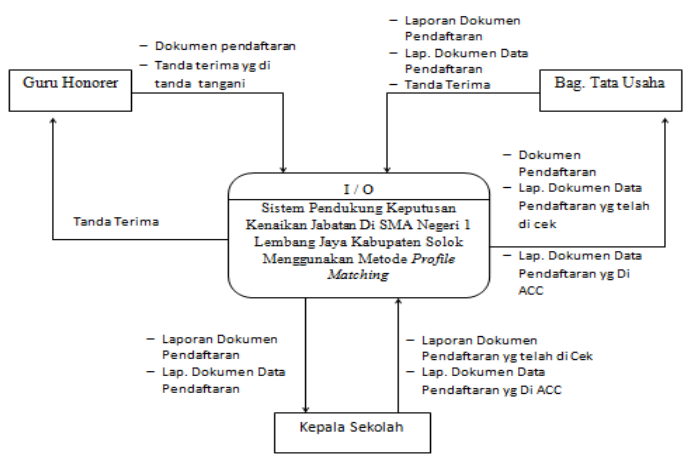

Gambar 2. Context Diagram

\subsection{Data Flow Diagram}

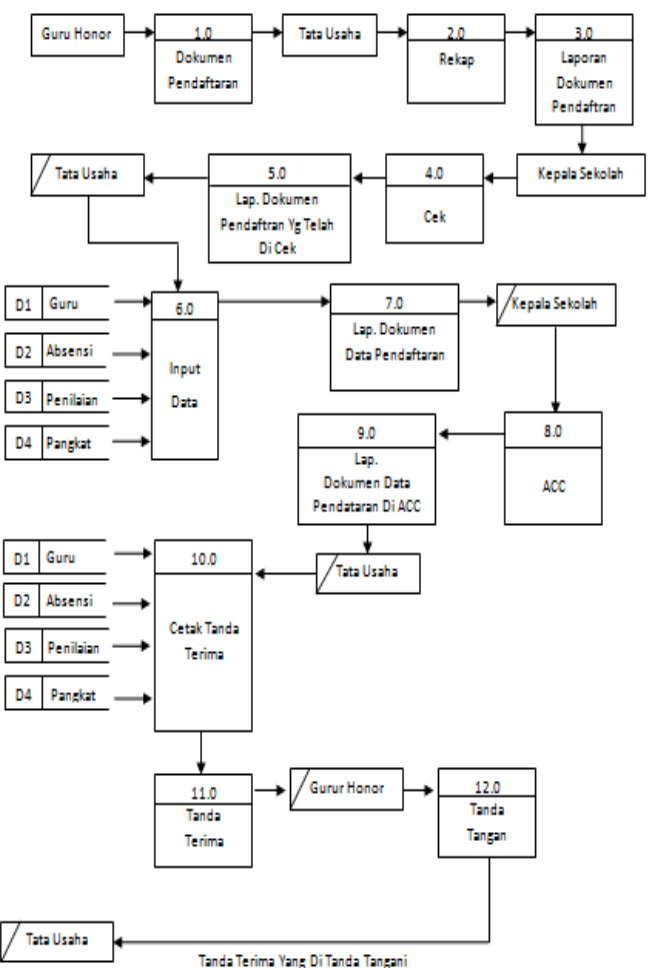

Gambar 3. Data Flow Diagram

\subsection{Entity Relationship Diagram (ERD)}

Model Entity Relationship Diagram (ERD) memperlihatkan hubungan atau relasi antara objek yang satu dengan objek yang lainnya, dengan kunci relasi (relasi key) sebagai kunci utama dari masing masing file. Pada diagram dibawah ini akan terlihat bagaimana entity yang ada dalam file - file yang digunakan. 


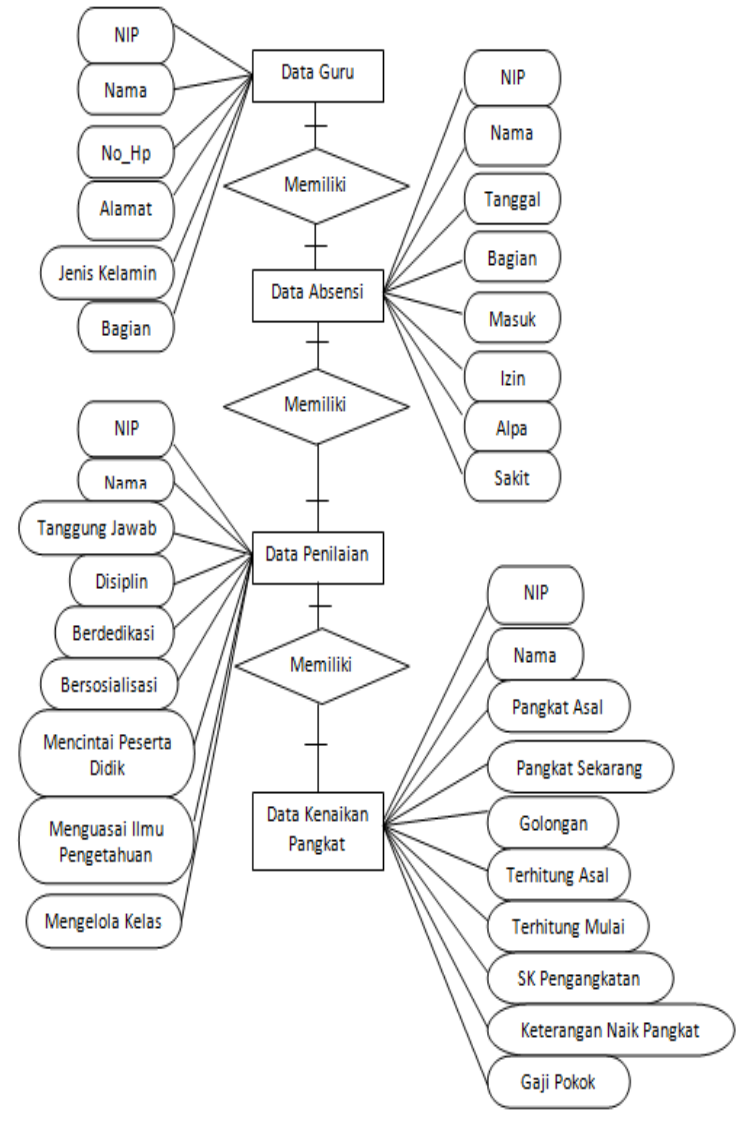

Gambar 4. Entity Relationship Diagram (ERD)

\section{HASIL DAN PEMBAHASAN Implementasi Sistem}

- Menu Login

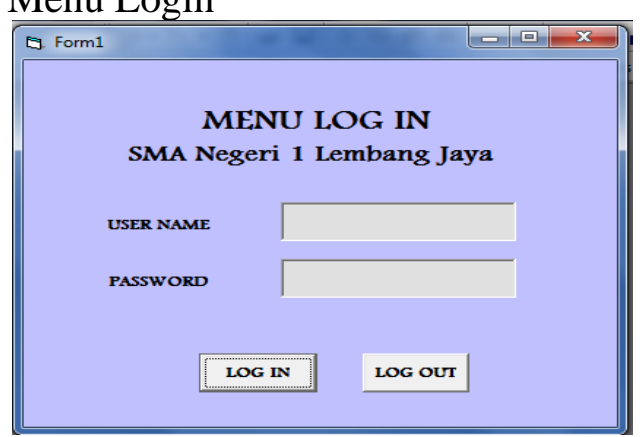

Gambar 5. Menu Login

- Menu Utama

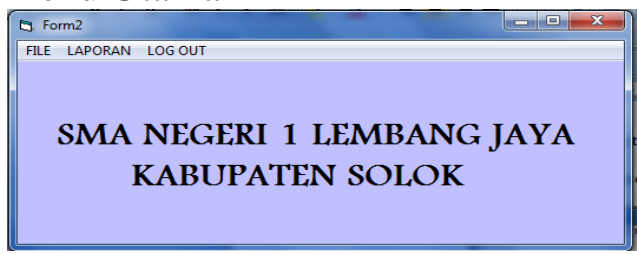

Gambar 6. Menu Utama

- Menu Input Data Guru

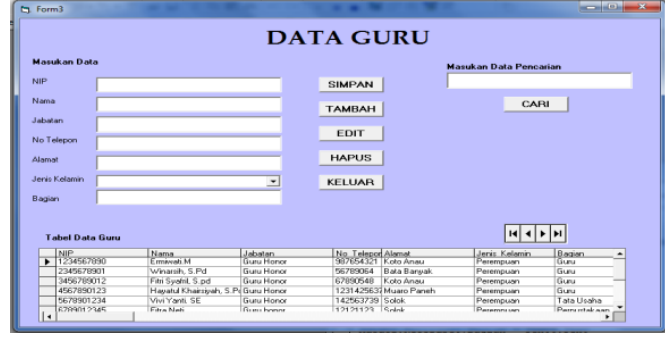

Gambar 7. Menu Input Data Guru

- Menu Input Data Absensi

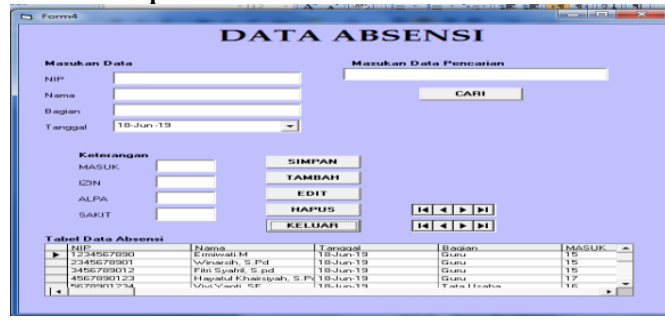

Gambar 8. Menu Input Data Absensi

- Menu Input Data Penilaian

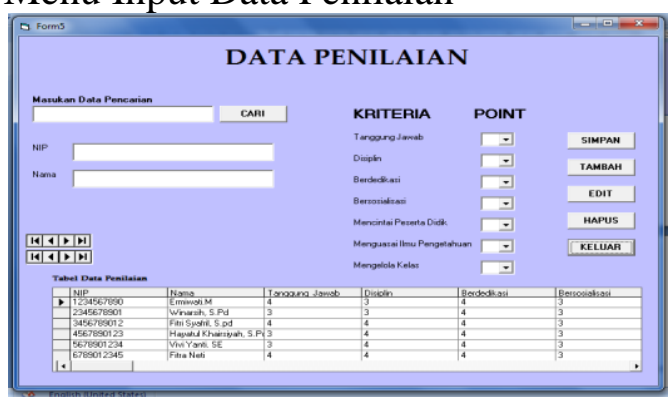

Gambar 9. Menu Input Data Penilaian

- Menu Proses Kenaikan Pangkat

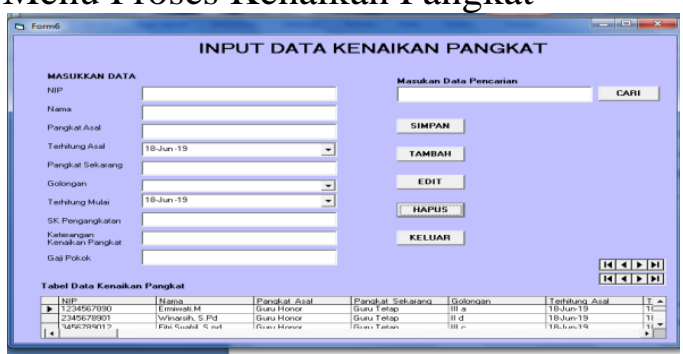

Gambar 10. Menu Proses Kenaikan Pangkat

- Menu Laporan

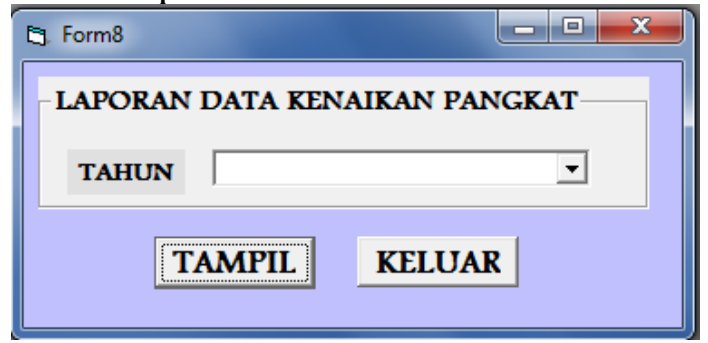

Gambar 11. Menu Laporan

- Tampilan Laporan 


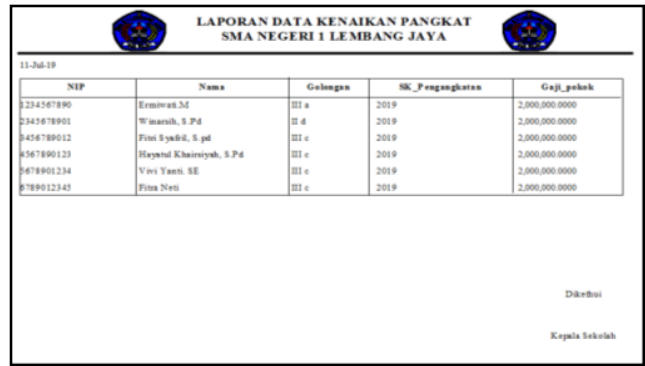

Gambar 12. Tampilan Laporan

\section{KESIMPULAN}

Beberapa kesimpulan yang dapat ditarik dari penelitian yang telah dilakukan, yaitu sistem pendukung keputusan untuk kenaikan pangkat di SMA Negeri 1 Lembang Jaya Kabupaten Solok menggunakan metode profile matching dan bahasa pemrograman Visual Basic 6.0 memberikan kemudahan dalam penyeleksian kenaikan pangkat untuk guru honor. Selain itu juga dapat membantu kepala sekolah untuk pengambilan keputusan kenaikan pangkat dengan penilaian menurut kriteria yang telah ditetapkan bagi si penerima pangkat dan untuk pembuatan laporan- laporan akan lebih efektif dan terstruktur.

\section{DAFTAR PUSTAKA}

H. Ari Suhartanto, Kusrini, "Decision Support System Untuk Penilaian Kinerja Guru Dengan Metode Profile Matching," $J$. Komput. Terap., vol. 2, no. 2, pp. 149158, 2016.

Fricles Ariwisanto Sianturi, "Implementasi Sistem Pendukung Keputusan Kenaikan Jabatan Guru Dengan Model Profile Matching Pada Sekolah Sma Swasta Raksana Medan," Mantik Penusa, vol. 18, no. 2, pp. 44-52, 2015.

F. Frieyadie, "Penggunaan Metode Profile Matching Untuk Sistem Penunjang Keputusan Kenaikan Jabatan Pada Instansi Pemerintah," Paradig. - J. Komput. dan Inform., vol. 18, no. 2, pp. 75-80, 2016.

H. Ariantono, M. Sudarma, and P. Arya Mertasana, "Rancang Bangun Sistem
Pendukung Keputusan Penentuan Kenaikan Posisi Jabatan Pada Instansi Pemerintahan Dengan Metode Profile Matching," J. Ilm. SPEKTRUM, vol. 2, no. 3, pp. 38-43, 2015.

K. Kusnadi, D. Martha, and A. Saputra, "Penerapan Metode Profile Matching Untuk Penilaian Kenaikan Jabatan Karyawan (Studi Kasus: Pt. Ilham Bangun Mandiri)," J. Digit, vol. 5, no. 2, pp. 146-158, 2017.

Priyanto Hidayatullah, "Visual Basic.Net Membuat Aplikasi Database dan Pemrograman Kreatif, Edisi Revisi,'Informatika, Bandung, 2015.

D. N. Sholihaningtias, "Sistem Pendukung Keputusan Kenaikan Jabatan," Sist. Pendukung Keputusan, vol. 2, no. 3, pp. 282-288, 2018.

J. I. Komputer and I. Volume, "Kata Kunci : Profile Matching, Kompetensi, Kenaikan pangkat, Sistem pendukung keputusan," vol. 6341, no. April, pp. 55-62, 2019.

K. Nisa, Kusrini, and Sudarmawan, "Sistem pendukung keputusan kenaikan pangkat karyawan," J. Inf. Politek. Indones. Surakarta, vol. 4, no. 3, 2018. 